\title{
Study of a gluten-free bread made from Gagome kelp (Kjellmaniella crassifolia Miyabe).
}

\author{
Masaharu Seguchi $^{{ }^{*}}$, Kyoko Iseki ${ }^{1}$, Aya Tabara ${ }^{2}$, Miki Takeuchi $^{3}$, Chieko Nakamura ${ }^{3}$ \\ ${ }^{1}$ Faculty of Home Economics, Laboratory of Food Technology, Kobe Women's University, Suma-ku, Kobe City \\ 654-8585, Japan \\ ${ }^{2}$ Department of Cooking and Confectionery, Confectionery Course, Osaka Seikei College, Osaka, 538-0044, Japan \\ ${ }^{3}$ Kobe Women's Junior College, Chuoo-Ku, Kobe City 650-0046, Japan
}

\begin{abstract}
Gluten-free bread was made from Gagome kelp, wheat starch, sugar, compressed yeast, and water. When the Gagome kelp was digested with pepsin or treated with ethyl ether, bread baked with the deproteinized or defatted Gagome kelp did not display worse properties. However, when the Gagome kelp was autoclaved at $120{ }^{\circ} \mathrm{C}$ for $100 \mathrm{~min}$, its bread making properties deteriorated markedly. A mixture of Gagome kelp and water was homogenized and centrifuged at $1,700 \mathrm{~g}$. The supernatant and precipitate were subjected to bread making tests. The results indicated that the supernatant fraction had good breadmaking properties. The supernatant was further dialyzed against a large amount of water and subjected to bread making tests. The undialyzable fraction display good bread making properties. The supernatant was divided into an upper transparent layer and a lower dark and viscous layer, and bread making tests were conducted. The upper transparent layer demonstrated better bread making properties than the lower dark and viscous layer.
\end{abstract}

Keywords: Gluten free bread, Kjellmaniella crassifolia Miyabe, Gagome kelp, Celiac disease (CD).

Accepted on 1 November, 2017

\section{Introduction}

Celiac disease (CD) is an autoimmune-type of gastrointestinal disorder that is triggered by gluten-containing grains, such as wheat, rye, barley, and oats [1]. With the advent of multiple serological tests for $\mathrm{CD}$, a substantial number of previously undiagnosed cases have been identified, yielding a prevalence of approximately $1 \%$ among the Caucasian population in the US and Europe [1,2]. Nakazawa et al. [3] used serological tests based on tissue transglutaminase-IgA (TTG-IgA) and histological examination to identify CD among the Japanese population. Their screening program among 710 patients identified seven cases $(0.98 \%)$ with both positive TTG-IgA and the pertinent mucosal changes, compatible with celiac disease, which study would shed light firstly on the discussion of possible diagnosis of celiac disease among East Asian population.

The only known treatment of celiac disease is the complete avoidance of wheat, rye, and barley [4]. In practice, commercial gluten-free products are formulated with a relatively short list of wheat-flour-replacing food-approved ingredients. Most commonly used are tapioca starch, rice flour, rice starch, potato starch, corn starch, egg whites, xanthan gum, guar gum, and HPMC (Hydroxyl Propyl Methyl Cellulose). Since commercial gluten-free bread formulas are highly proprietary, more useful and safety gluten-free bread formulas are searched [5]. Japanese people like sticky foods such as yam flour, gagome kelp, Natto (fermented soybean), Okura (Abelmoschus esculentus), Nameko (Pholiota microspore (Berk.) Sacc.), and Mozuku (Nemacystus decipiens) which are all low cost diet and will be accepted by people in all over the world, so we would like to use these viscous food materials in gluten-free diets.

Gagome kelp (Kjellmaniella crassifolia Miyabe), which is more viscous than wheat gluten can be used to make glutenfree bread. Gagome kelp is grown in the Hakodate area of Hokkaido in Japan and is considered to have beneficial health effects [6]. Gagome kelp contains water-soluble polysaccharides, which are widely used as a thickener in the low-calorie food sector and as a hemostatic agent or a humectant in the medical sector. It is commercially reported that Gagome kelp contains alginate (19.0-22.0 g), laminarin (4.0-4.5 g), and fucoidan (3.5-4.5 g per $100 \mathrm{~g})$, and absorbs water in the stomach to produce a sticky substance. The chemical structures of alginate, laminarin, and fucoidan molecules found in kelp were reported by Teruya et al., Kadam et al. and Tako et al. [7-9] respectively. Alginate is a linear, 1,4linked copolymer of $\alpha$-L-gluronate and $\beta$-D-mannuronate, and has been reported to protect cells from apoptosis, induce cytokine secretion, and regulate the uptake of cholesterol and glucose [10]. Laminarin is a storage $\beta$-glucan composed of 1,3$\beta$-D-glucan and $\beta$-1,6-linked branches, and it has many biofunctional activities including antitumour, anti-apoptotic, anti-inflammatory, anticoagulant, and antioxidant activity [8]. Fucoidan is a fucose-containing sulfated polysaccharide and exhibits anti-allergic activity, anti-infectious effects against Helicobacter pylori and prions, and anti-tumor activity [6].

We have published reports about the production of gluten-free bread using yam flour [11] and banana flour [12], but neither of 
Citation: Seguchi M, Iseki K, Tabara A, et al. Study of a gluten-free bread made from Gagome kelp (Kjellmaniella crassifolia Miyabe). J Biochem Biotech. 2017;1(1):25-30.

these flours was as viscous as Gagome kelp, so it is possible to make bread with a smaller amount of Gagome kelp than yam or banana flour. The bread making properties of Gagome kelp, such as the height $(\mathrm{mm})$ and specific volume $\left(\mathrm{cm}^{3} / \mathrm{g}\right)$ of the bread it produces were comparable with those of wheat bread [13]. To know clear contribution of Gagome kelp in this gluten- free bread making experiment we used a similar formula to wheat sweet dough, which composed of 14-22 g sugar, 1.5-2.0 $\mathrm{g} \mathrm{NaCl}, 1.5-4.5 \mathrm{~g}$ of dry-yeast, $100 \mathrm{~g}$ wheat flour and 40-50 g water.

\section{Materials and Methods}

\section{Materials}

Gagome kelp was purchased from commercial sources. The Gagome kelp was lightly washed with water, cut into small pieces, crushed in a Waring blender (Hamilton Beach/ProctorSilex, Inc., Southern Pines, NC, USA), and freeze-dried at -15 ${ }^{\circ} \mathrm{C}$ for $70 \mathrm{~h}$ in a Kyowa RLE-120 freeze-drier (Kyowa Vacuum Engineering Co., Ltd., Tokyo, Japan). A general compositional analysis of the Gagome kelp obtained the following findings: moisture, $10.13 \%$; protein, $11.79 \%$; fat, $0.58 \%$; and ash content, $17.11 \%$; respectively. Protein conversion calculations were carried out using the formula Nx5.7 [14]. Ash content was determined using the AACC International Method (08-01, 2000 ) at a moisture content of $14.0 \%$. Moisture content was determined using the method of Tsutsumi and Nagahara [15]. Pepsin from the porcine stomach mucosa was purchased from Wako Pure Chemical Industries, Ltd. (Osaka, Japan).

\section{Pepsin digestion of Gagome kelp}

The treatment of Gagome kelp with pepsin was performed according to the method of Seguchi [16]. The Gagome kelp $(3.0 \mathrm{~g})$ was mixed in a $120 \mathrm{ml}(\mathrm{pH} 2.0) \mathrm{HCl}$ suspension of pepsin $(3 \mathrm{mg})$ and then incubated at $37^{\circ} \mathrm{C}$ for $60 \mathrm{~min}$ with stirring. Then, the suspension was centrifuged at $1,700 \mathrm{~g}$ for 10 min, and the precipitated Gagome kelp was washed with water $(120 \mathrm{ml}) 10$ times and dried at room temperature.

\section{Defatting of Gagome kelp with ethyl ether}

Gagome kelp (10 g) was subjected to ethyl ether extraction (at $65^{\circ} \mathrm{C}$ ) in a Soxhlet apparatus for $8 \mathrm{hs}$.

\section{Autoclaving treatment of Gagome kelp}

Gagome kelp (30 g) was suspended in $40 \mathrm{ml}$ of water, heated at $127^{\circ} \mathrm{C}$ for $100 \mathrm{~min}$ in an autoclave (Shimadzu, Kyoto, Japan), and then cooled until use [12]. Although the $\mathrm{pH}$ in Gagome kelp suspension was not determined, it may be neutral.

\section{Bread making}

Bread making was made in the following manner: $300 \mathrm{mg}$ Gagome kelp, $30.5 \mathrm{~g}$ wheat starch, $8.86 \mathrm{~g}$ sugar, $10 \mathrm{~g}$ compressed yeast and $50 \mathrm{ml}$ water were mixed in a 3.6-L bowl using a kitchen aid mixer (Kenmix Chef Aicoh Mixers and Aicoh Systems Co., Ltd., Japan) for $9 \mathrm{~min}$ at $116 \mathrm{rpm}$. The homogenized dough was placed into a pan $\left(5.5 \times 9.5 \times 6.6 \mathrm{~cm}^{3}\right)$, proofed in an oven at $40{ }^{\circ} \mathrm{C}$ for $20 \mathrm{~min}$, and baked at $210{ }^{\circ} \mathrm{C}$ for $10 \mathrm{~min}$ (Sanyo Drying Oven MOV-212, Sanyo Co. Ltd., Japan). After being baked, the bread was removed from the pan and cooled for $1 \mathrm{~h}$ at room temperature $\left(26{ }^{\circ} \mathrm{C}\right)$ at a relative humidity of $43 \%$. The height $(\mathrm{mm})$, weight $(\mathrm{g})$, and volume $\left(\mathrm{cm}^{3}\right)$ of the bread were measured, and bread crumbs were evaluated visually. Bread volume was measured using the rapeseed displacement method. The color ( $L, a$, and $b$ values) of the bread crumbs was evaluated using an $L, a$, and $b$ color specification system based on a chromaticity diagram and a Hunter Lab Color Meter NE 2000 (Nippon Denshoku Co., Ltd., Tokyo, Japan). Positive values for $L, a$, and $b$ indicate white, red, and yellow, respectively. Negative values for $a$ indicate green.

\section{Fractionation of Gagome kelp/water into supernatant and precipitate fractions by centrifugation}

Gagome kelp (3.6 g)/ water $(264 \mathrm{ml})$ was homogenized in a Waring blender with vigorous shaking (10,000 rpm for $2 \mathrm{~min})$ and centrifuged at 1,700 g for $10 \mathrm{~min}$. The supernatant and precipitate (Figure 1) were collected, freeze-dried, and subjected to bread making tests.

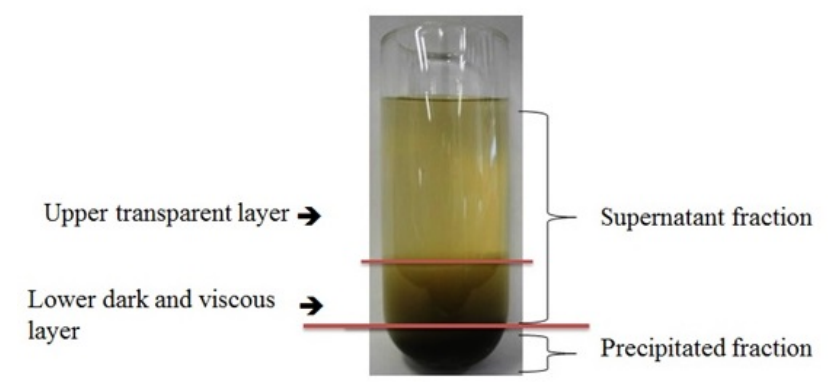

Figure 1. Separation of the supernatant and precipitate and the subsequent separation of the supernatant into an upper transparent layer and a lower dark and viscous layer.

\section{Separation of the supernatant into high molecular weight (HMW) and low molecular weight (LMW) fractions by dialysis}

A dialysis tube having MWCO (molecular weight cutoff), 12,000-14,000 Daltons and pore size $24 \mathrm{~A}^{\circ}$ ( Nihon Medical Science Co., Ltd., Takasaki, Japan) was used to dialyze. The supernatant was dialyzed against $10 \mathrm{~L}$ of water overnight in a cold room $\left(4^{\circ} \mathrm{C}\right)$ and separated into undialyzable (HMW) and dialyzable (LMW) fractions.

The undialyzable fraction (in the dialysis tube) was freezedried at $-15{ }^{\circ} \mathrm{C}$ for $72 \mathrm{~h}$ and crushed; this was termed the HMW fraction (its moisture content was not determined). The dialyzable fraction was concentrated to syrup at $65{ }^{\circ} \mathrm{C}$ using a rotary evaporator (RE-51, Yamato Scientific Co., Ltd., Tokyo, Japan) and was termed the LMW fraction. 


\section{Determination of the viscosity of the Gagome kelp supernatant}

The viscosity of the Gagome kelp supernatant was measured at room temperature using a B-type viscometer (Brookfield Engineering Labs Inc., MA, USA).

\section{Fractionation of the supernatant into upper transparent and lower dark and viscous layers by centrifugation}

The supernatant was composed of an upper transparent layer and a lower dark and viscous layer (Figure 1). The two layers were collected, freeze-dried, and used for bread making.

\section{Statistical analysis}

A statistical software package (SPSS Inc., Chicago, IL, USA) was used for the statistical analyses. Three or more loaves of bread were baked for each experiment. Bread height $(\mathrm{mm})$ and specific volume $\left(\mathrm{cm}^{3} / \mathrm{g}\right)$ were measured three or more for each sample and averaged. Data with significant $F$ values were subjected to analysis of variance, followed by Duncan's multiple range tests for comparison of means.

\section{Results and Discussion}

\section{Optimal amounts of ingredients for bread making with Gagome kelp}

To determine the optimal amounts of ingredients for bread making with Gagome kelp, bread making tests were performed using various combinations of 50-700 mg Gagome kelp, 29.80-30.45 g wheat starch, $8.86 \mathrm{~g}$ sugar, $10 \mathrm{~g}$ compressed yeast, and $18-30 \mathrm{ml}$ water. In bread making tests involving 300 mg Gagome kelp, $30.2 \mathrm{~g}$ wheat starch, $8.86 \mathrm{~g}$ sugar, $10 \mathrm{~g}$ compressed yeast, and 18 to $30 \mathrm{ml}$ of water (Table 1), the maximum bread height was obtained when 22-24 ml water were used.

The resulting breads exhibited the following properties: $22 \mathrm{ml}$ water: bread height; $79.56 \mathrm{~mm}$, specific volume; $6.89 \mathrm{~cm}^{3} / \mathrm{g}$ : $24 \mathrm{ml}$ water: bread height; $84.04 \mathrm{~mm}$, specific volume; 6.67 $\mathrm{cm}^{3} / \mathrm{g}$. Those results were higher than bread making properties as Haruyutaka wheat flour (bread height, $69.4 \mathrm{~mm}$ and specific volume, $3.45 \mathrm{~cm}^{3} / \mathrm{g}$ ) [13].

Thus, it was determined that the best Gagome kelp bread was made with $300 \mathrm{mg}$ Gagome kelp, $30.2 \mathrm{~g}$ wheat starch, $8.86 \mathrm{~g}$ sugar, $10 \mathrm{~g}$ compressed yeast, and 22-24 $\mathrm{ml}$ water. It was calculated that flour (Gagome kelp+wheat starch) $30.5 \mathrm{~g}$ (100\%), sugar $8.86 \mathrm{~g}(29.1 \%)$, and dry yeast (compressed yeast $10 \mathrm{~g}=$ around $9 \mathrm{~g}$ water and $1 \mathrm{~g}$ dry yeast) $3.3 \%$ were obtained.

This was a similar formula to wheat sweet dough for coffee sweet bread. Seguchi et al. [11] reported that they could obtain a nice bread making properties such as bread height and specific volume $\left(68.4 \mathrm{~mm}\right.$ and $\left.3.95 \mathrm{~cm}^{3} / \mathrm{g}\right)$ using yam flour $(10$ g). Seguchi et al. [12] also obtained same nice bread height and specific volume, $69.4 \mathrm{~mm}$ and $3.45 \mathrm{~cm}^{3} / \mathrm{g}$, respectively in banana flour $(30 \mathrm{~g})$.
The amount of Gagome kelp flour (300 mg) was extensively small amount than that of yam flour or banana flour to obtain maximum bread making properties, which was due to higher viscosity of Gagome kelp flour, and which is effectively convenient to the bread flavor and bread color. The gluten-free bread indicated whitish bread and lower flavor by the addition of Gagome kelp, which may be suitable for consumer.

Table 1. Bread making properties baked with Gagome kelp (300 mg) and various water (Values represent means of three or more replicates with SD in parentheses. Means followed by different letters in columns are significantly at $\mathrm{p}<0.05$ according to Duncan's multiple range test).

\begin{tabular}{llllll}
\hline $\begin{array}{l}\text { Water } \\
(\mathrm{ml})\end{array}$ & $\begin{array}{l}\text { Breadheight } \\
(\mathrm{mm})\end{array}$ & $\begin{array}{l}\text { Specificvolume } \\
\left(\mathrm{cm}^{3} / \mathrm{g}\right)\end{array}$ & $L$ & $a$ & $b$ \\
\hline 18 & $65.44^{\mathrm{a}}(2.22)$ & $5.56^{\mathrm{a}}(0.28)$ & 61.82 & -0.94 & 8.1 \\
\hline 20 & $72.38^{\mathrm{b}}(4.03)$ & $5.88^{\mathrm{a}}(0.42)$ & 65.99 & -1.74 & 8.64 \\
\hline 22 & $79.56^{\mathrm{c}}(3.05)$ & $6.89^{\mathrm{b}}(0.39)$ & 65.7 & -0.9 & 8.21 \\
\hline 24 & $84.04^{\mathrm{c}}(3.37)$ & $6.67^{\mathrm{b}}(0.30)$ & 66.09 & -1.13 & 7.34 \\
\hline 26 & $78.74^{\mathrm{c}}(1.92)$ & $5.44^{\mathrm{c}}(0.15)$ & 68.59 & -0.51 & 8.26 \\
\hline 28 & $64.01^{\mathrm{d}}(4.17)$ & $3.96^{\mathrm{d}}(0.11)$ & 71.99 & -0.53 & 8.03 \\
\hline 30 & $63.81^{\mathrm{d}}(9.63)$ & $3.96^{\mathrm{d}}(0.57)$ & 67.78 & -1.41 & 8.96 \\
\hline
\end{tabular}

\section{Effects of subjecting Gagome kelp to various treatments on its bread making properties}

To clarify the key components in Gagome kelp for bread making, Gagome kelp was subjected to pepsin treatment, ethyl ether extraction, or autoclaving treatment before being used for bread making. The results of these experiments are shown in Table 2. Pepsin was able to digest the proteins in Gagome kelp, and ethyl ether was able to defat Gagome kelp.

Table 2. Effects of various treatments of Gagome kelp on bread making properties (Values represent means of three or more replicates with SD in parentheses. Means followed by different letters in columns are significantly at $\mathrm{p}<0.05$ according to Duncan's multiple range tests).

\begin{tabular}{llllllll}
\hline Treatments & Bread height & \multicolumn{2}{c}{$\begin{array}{l}\text { Specific } \\
\text { volume }\end{array}$} & $L$ & $a$ & $b$ \\
\hline & $(\mathrm{mm})$ & $(\%)$ & $\left(\mathrm{cm}^{3} / \mathrm{g}\right)$ & $(\%)$ & & \\
\hline None & $79.56^{\mathrm{a}}(3.05)$ & 100 & $6.89^{\mathrm{a}}(0.39)$ & 100 & 65.7 & -0.9 & 8.21 \\
\hline Pepsin & $81.68^{\mathrm{a}}(3.82)$ & 103 & $6.12^{\mathrm{a}}(0.42)$ & 89 & 71.82 & 7 & 8.09 \\
\hline Ethyl ether & $83.95^{\mathrm{a}}(6.24)$ & 106 & $6.63^{\mathrm{a}}(0.70)$ & 96 & 64.71 & 4 & 8.03 \\
\hline Autoclave & $23.81^{\mathrm{b}}(0.58)$ & 30 & $1.54^{\mathrm{b}}(0.05)$ & 22 & 61.55 & 6 & 13.38 \\
\hline
\end{tabular}

However, neither treatment affected the bread making properties of Gagome kelp (after pepsin treatment: bread height: $81.68 \mathrm{~mm}(103 \%)$, specific volume: $6.12 \mathrm{~cm}^{3} / \mathrm{g}(89 \%)$ : after ethyl ether treatment: bread height: $83.95 \mathrm{~mm}(106 \%)$, specific volume: $\left.6.63 \mathrm{~cm}^{3} / \mathrm{g}(96 \%)\right)$. Thus, it was clear that 
Citation: Seguchi M, Iseki K, Tabara A, et al. Study of a gluten-free bread made from Gagome kelp (Kjellmaniella crassifolia Miyabe). J

protein and fat in Gagome kelp do not influence its bread making properties.

Conversely, subjecting Gagome kelp to autoclaving treatment $\left(127^{\circ} \mathrm{C}, 100 \mathrm{~min}\right)$ caused a marked reduction in its bread making properties (bread height: $23.81 \mathrm{~mm}$ (30\%), specific volume: $\left.1.54 \mathrm{~cm}^{3} / \mathrm{g}(22 \%)\right)$. It was suggesting that the good bread making properties of Gagome kelp are caused by its heat labile components: i. e., components other than enzymes.

\section{Purification of the key bread making components of Gagome kelp}

Next, we tried to purify the key bread making components of Gagome kelp. After homogenizing Gagome kelp with water and centrifuging it at $1,700 \mathrm{~g}$ for $10 \mathrm{~min}$. the precipitate $(1.19$ g, 33.1\%) and supernatant (2.11 g, 58.6\%) from Gagome kelp
(3.60 g, 100\%) were obtained, which were then freeze-dried and subjected to bread making tests (Table 3 ).

The bread making tests were performed according to viscosity of bread dough using various amounts of the supernatant or the precipitate, and finally baked with $180 \mathrm{mg}$ of the supernatant and $22 \mathrm{ml}$ of water, or $110 \mathrm{mg}$ of the precipitate and $22 \mathrm{ml}$ of water to their optimal bread making properties. The precipitate exhibited poor bread making properties (bread height: 26.34 $\mathrm{mm}$, specific volume: $1.48 \mathrm{~cm}^{3} / \mathrm{g}$ ), whereas the supernatant displayed good bread making properties (bread height: 83.48 $\mathrm{mm}$, specific volume: $6.59 \mathrm{~cm}^{3} / \mathrm{g}$ ).

Therefore, it was shown that the key components for bread making are present in the water soluble fraction of Gagome kelp.

Table 3. Bread baked with supernatant and precipitation fractions (Values represent means of three or more replicates with SD in parentheses. Means followed by different letters in columns are significantly at $\mathrm{p}<0.05$ according to Duncan's multiple range test).

\begin{tabular}{|c|c|c|c|c|c|c|}
\hline Sample (mg) & Water (ml) & Bread height $(\mathrm{mm})$ & Specific volume $\left(\mathrm{cm}^{3} / \mathrm{g}\right)$ & $L$ & $a$ & $b$ \\
\hline \multirow{4}{*}{ Supernatant $180 \mathrm{mg}$} & 20 & $55.36^{\mathrm{a}}(7.43)$ & $4.50^{\mathrm{a}}(0.43)$ & 65.92 & -1.21 & 9.36 \\
\hline & 22 & $83.48^{\mathrm{b}}(9.22)$ & $6.59^{\mathrm{b}}(0.70)$ & 70.16 & -0.91 & 7.57 \\
\hline & 24 & $53.69^{a}(2.52)$ & $3.67^{\mathrm{c}}(0.17)$ & 65.16 & -0.91 & 7.6 \\
\hline & 26 & $51.56^{a}(2.63)$ & $3.46^{c}(0.39)$ & 71.85 & -1 & 9.88 \\
\hline \multirow{4}{*}{ Precipitation 110 mg } & 20 & $26.13^{\mathrm{a}}(1.12)$ & $1.42^{\mathrm{a}}(0.07)$ & 71.81 & -0.48 & 14.7 \\
\hline & 22 & $26.34^{a}(0.82)$ & $1.48^{\mathrm{a}}(0.04)$ & 72.99 & -0.91 & 14.94 \\
\hline & 24 & $26.16^{a}(0.76)$ & $1.32^{\mathrm{b}}(0.08)$ & 67.94 & -1.58 & 13.83 \\
\hline & 26 & $27.95^{\mathrm{b}}(0.71)$ & $1.33^{\mathrm{b}}(0.05)$ & 62.42 & -1.87 & 13.18 \\
\hline
\end{tabular}

\section{Separation of the supernatant into HMW and LMW fractions by dialysis}

Furthermore, the supernatant obtained from Gagome kelp (3.32 g) was dialyzed against $10 \mathrm{~L}$ water, and the undialyzable (HMW, $1.34 \mathrm{~g}, 61.8 \%$ ) and dialyzable (LMW, $0.83 \mathrm{~g}, 38.3 \%$ ) fractions were separated and freeze-dried.

The optimal bread making properties were obtained with 110 mg of the HMW fraction and less than $20 \mathrm{ml}$ of water, or 70 $\mathrm{mg}$ of the LMW fraction and 24-26 ml of water (HMW fraction: bread height; more than $79.10 \mathrm{~mm}$, specific volume: $5.88 \mathrm{~cm}^{3} / \mathrm{g}$.

Those data may be higher if addition of water was smaller: LMW fraction: bread height: $29.28 \mathrm{~mm}$, specific volume: 1.33 $\mathrm{cm}^{3} / \mathrm{g}$ ) (Figure 2 and Table 4).

It was clear that the key components for bread making were present in the HMW fraction.

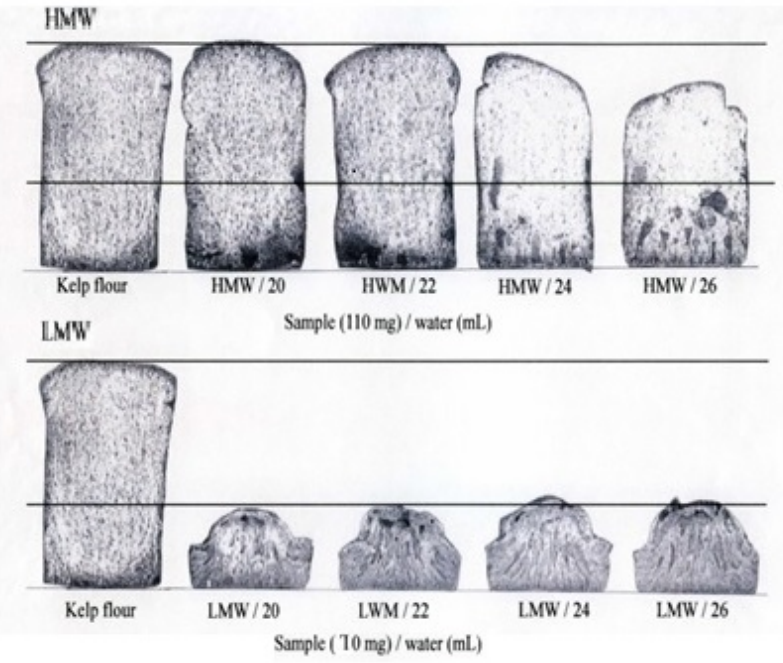

Figure 2. Cross-sections of bread baked with the HMW or LMW fraction Bread making conditions: $110 \mathrm{mg}$ HMW fraction or $70 \mathrm{mg}$ LMW fraction were used.

The dialyzable LMW fraction was spotted on paper, dried and sprayed with two reagents (ninhydrin and AHP (Aniline Hydrogen Phthalate)), respectively, and it was realized that LMW fraction only contained ninhydrin-positive materials, 
such as amino acids and peptides; i.e., it did not contain AHPpositive materials of carbohydrates (data were not shown here).

Table 4. Bread baked with HMW or LMW fraction in Gagome kelp (Values represent means of three or more replicates with SD in parentheses. Means followed by different letters in columns are significantly at $\mathrm{p}<0.05$ according to Duncan's multiple range test).

\begin{tabular}{|c|c|c|c|c|c|c|}
\hline Sample (mg) & $\begin{array}{l}\text { Water } \\
(\mathrm{ml})\end{array}$ & $\begin{array}{l}\text { Bread height } \\
(\mathrm{mm})\end{array}$ & $\begin{array}{l}\text { Specific volume } \\
\left(\mathrm{cm}^{3} / \mathrm{g}\right)\end{array}$ & $L$ & $a$ & $b$ \\
\hline \multirow{4}{*}{ HMW 110 mg } & 20 & $79.10^{\mathrm{a}}(3.55)$ & $5.88^{a}(0.26)$ & 64.85 & -0.84 & 8.51 \\
\hline & 22 & $70.60^{a}(6.19)$ & $5.20^{\mathrm{b}}(0.32)$ & 65.82 & -0.94 & 8.04 \\
\hline & 24 & $68.22^{\mathrm{a}}(3.73)$ & $4.72^{\mathrm{b}}(0.26)$ & 68.92 & -0.52 & 7.2 \\
\hline & 26 & $51.90^{\mathrm{b}}(7.42)$ & $3.46^{\mathrm{c}}(0.30)$ & 68.04 & -0.09 & 9.56 \\
\hline \multirow{4}{*}{ LMW 70 mg } & 20 & $25.29^{a}(1.45)$ & $1.24^{\mathrm{a}}(0.02)$ & 68.46 & -0.34 & 11.51 \\
\hline & 22 & $26.98^{a}(0.58)$ & $1.29^{a}(0.04)$ & 65.81 & -0.78 & 12.64 \\
\hline & 24 & $29.28^{a}(1.43)$ & $1.33^{a}(0.03)$ & 68.35 & -0.59 & 11.34 \\
\hline & 26 & $27.33^{c}(1.21)$ & $1.33^{a}(0.07)$ & 62.7 & -1.16 & 10.41 \\
\hline
\end{tabular}

\section{Autoclaving-induced changes in the viscosity of the supernatant and the effects on the supernatant's bread making properties}

The supernatant of Gagome kelp was subjected to autoclaving treatment $\left(127^{\circ} \mathrm{C}, 100 \mathrm{~min}\right)$, and its viscosity was measured.

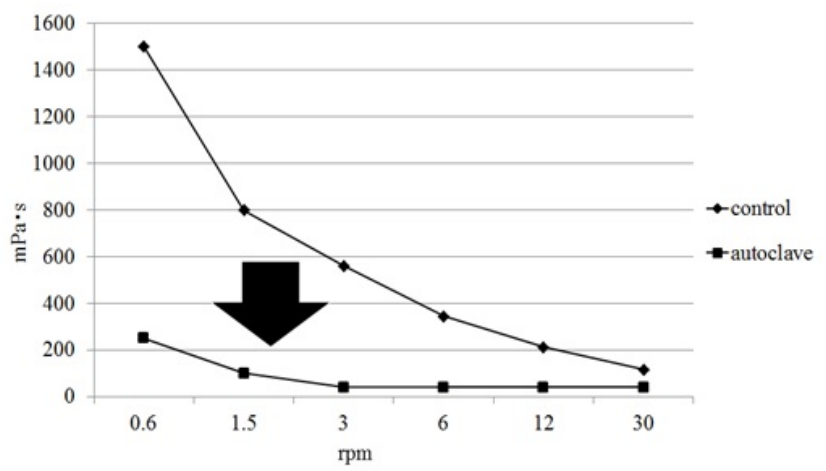

Figure 3. Autoclaving-induced changes in the viscosity of the Gagome kelp supernatant.

The viscosity of the supernatant decreased after the autoclaving treatment (Figure 3), and its bread making properties in baking tests with $180 \mathrm{mg}$ sup and $22 \mathrm{ml}$ water deteriorated: autoclaved supernatant: bread height; $27.14 \mathrm{~mm}$, specific volume: 1.41 $\mathrm{cm}^{3} / \mathrm{g}$ : unautoclaved supernatant fraction: bread height: 83.48 $\mathrm{mm}$, specific volume: $6.59 \mathrm{~cm}^{3} / \mathrm{g}$ (Figure 4).

It was clear that the reduction in the viscosity of the autoclaved supernatant was related to the deterioration of its bread making properties.

Although the viscous materials in Gagome kelp, such as alginic acid, laminarin, and fucoidan, are all water-soluble HMW polysaccharides, it remains unclear whether they are heat labile.

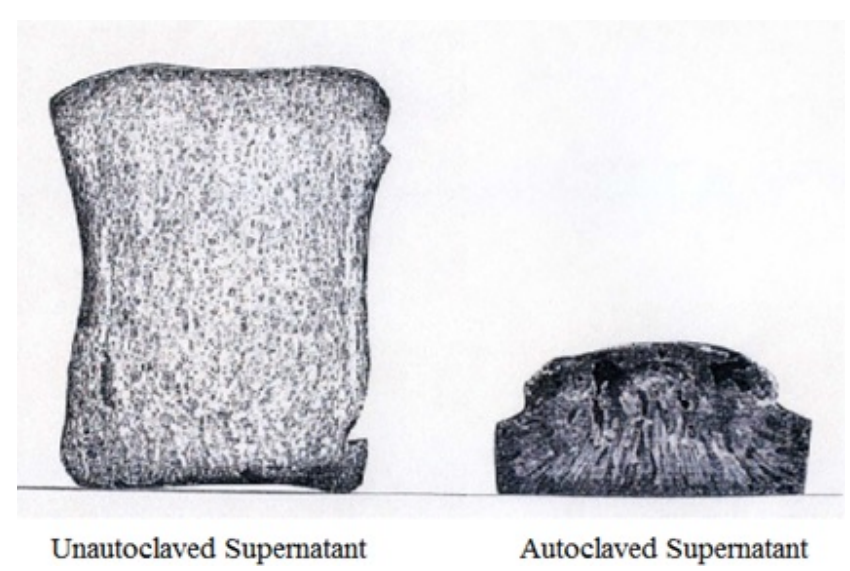

Figure 4. Cross-sections of bread baked with the autoclaved supernatant.

\section{Fractionation of the supernatant into upper transparent and lower dark and viscous layers by centrifugation}

The supernatant of Gagome kelp (14.4 g, $100 \%)$ contained two layers (Figure 1), an upper transparent layer $(2.10 \mathrm{~g}, 14.6$ $\%$ ) and a lower dark and viscous layer(5.86 g, 40.7\%). These layers were separated, freeze-dried, and subjected to bread making tests. According to viscosity of bread dough, sample $150 \mathrm{mg}$ and water $22 \mathrm{ml}$ were selected. The results (Table 5) indicated that the bread making properties of two layers were as follows: upper transparent layer: bread height: $62.56 \mathrm{~mm}$, specific volume: $4.84 \mathrm{~cm}^{3} / \mathrm{g}$ : lower dark and viscous layer: bread height: $57.61 \mathrm{~mm}$, specific volume: $3.64 \mathrm{~cm}^{3} / \mathrm{g}$. Thus, it was found that the upper transparent layer had better bread making properties.

Table 5. Bread baked with upper or lower layer in supernatant fraction of Gagome kelp (Values represent means of three or more replicates with $\mathrm{SD}$ in parentheses).

\begin{tabular}{lllllll}
\hline $\begin{array}{l}\text { Sample } \\
(150 \mathrm{mg})\end{array}$ & $\begin{array}{l}\text { Water } \\
(\mathrm{ml})\end{array}$ & $\begin{array}{l}\text { Bread } \\
\text { height } \\
(\mathrm{mm})\end{array}$ & $\begin{array}{l}\text { Specific } \\
\text { volume } \\
\left(\mathrm{cm}^{3} / \mathrm{g}\right)\end{array}$ & $L$ & $a$ & $b$ \\
\hline & 22 & $\begin{array}{l}62.56 \\
(4.61)\end{array}$ & $\begin{array}{l}4.84 \\
(0.54)\end{array}$ & 70.39 & -0.58 & 8.77 \\
Upper layer & 22 & 57.61 & $\begin{array}{l}3.64 \\
(0.45)\end{array}$ & 52.67 & -1.21 & 7.16 \\
\hline
\end{tabular}

However, the amount of the lower dark and viscous layer $(73.6 \%)$ was larger than that of the upper transparent layer (26.4\%). In this study, we did not extract alginate, laminarin, and fucoidan from Gagome kelp: however, the upper transparent layer or the lower dark viscous layer of the supernatant might have contained these polysaccharides.

\section{Conclusion}

It was shown that gluten-free bread can be made with $300 \mathrm{mg}$, Gagome kelp, $30.2 \mathrm{~g}$ wheat starch, $8.86 \mathrm{~g}$ sugar, $10 \mathrm{~g}$ compressed yeast, and $22.0 \mathrm{ml}$ water. The water-soluble fraction of Gagome kelp exhibited good bread making properties; however, its bread making properties deteriorated 
Citation: Seguchi M, Iseki K, Tabara A, et al. Study of a gluten-free bread made from Gagome kelp (Kjellmaniella crassifolia Miyabe). J

after autoclaving treatment, suggesting that alginate, laminarin, and fucoidan are important for making bread from Gagome kelp.

\section{Reference}

1. Green PH, Cellier C. Celiac disease. The New England journal of medicine. 2007;357:1731-43.

2. Fasano A, Berti I, Gerardduzzi T, et al. Prevalence of celiac in at-risk and not-at-risk groups in the United States; a large multicenter study. Arch intern med. 2003;163,286-92.

3. Nakazawa H, Makishima H, Ito T, et al. Screening tests using serum tissue transglutaminase IgA may facilitate the identification of undiagnosed celiac disease among Japanese population. Int. J Med Sci. 2014;11:819-23.

4. Fasano A, Catassi C. Current approaches to diagnosis and treatment of celiac disease: An evolving spectrum. Gastroenterology. 2001;120:636-51.

5. Casper JL, Atwell WA. Gluten-Free Baked Product. St. Paul. Minn.: AACC International, Inc St Paul, Minnesota. 2014;58.

6. Yan H, Kakuta S, Nishihara M, et al. Kjellmaniella crassifolia Miyabe (Gagome) extract modulates intestinal and systemic immune responses. Biosci Biotechnol Biochem. 2011;75:2178-83.

7. Teruya T, Tamaki Y, Konishi $T$, et al. Rheological characteristics of Alginate isolated from commercially cultured Nemacystus decipiens (Itomozuku). J Appl Glycosci. 2010;57:7-12.

8. Kadam SU, Tiwari BK, O’Donnell CP. Extraction, structure and biofunctional activities of laminarin from brown algae. Food Science \& Technology. 2015;50:24-31.

9. Tako M, Nakada T, Hongou F. Chemical characterization of Fucoidan from commercially cultured Nemacystus decipiens (Itomozuku). Biosci Biotechnol Biochem. 1999;63:1813-5.

10. Tusi SK, Khalaj L, Ashabi G, et al. Alginate oligosaccharide protects against endoplasmic reticulum and mitochondrial-mediated apoptotic cell death and oxidative stress. Biomaterials. 2011;32:5438-58.

11. Seguchi M, Ozawa M, Nakamura C, et al. Development of gluten-free bread baked with yam flour. Food Sci Technol Res. 2012;18:543-8.

12. Seguchi M, Tabara A, Iseki K, et al. Development of Gluten-Free Bread Baked with Banana (Musa spp.) Flour. Food Sci Technol Res. 2014;20:613-9.

13. Seguchi M, Abe M. Effect of leek (A.ampeloprasum L.) and scallion (A Chinense L.) on bread making properties. Food Sci Technol Res. 2004;10:479-82.

14. AACC International. Approved Methods of the American Association of Cereal Chemists, 10th Ed, Method 08-01 and 46-10, The Association: St. Paul, MN. 2000.

15. Tsutsumi C, Nagahara T. Effect of drying temperatures on the moisture determination of starches by oven drying method. Shokuryou Kagaku Kenkyu Hokoku. 1961;15:118-9.

16. Seguchi M. Oil-binding capacity of prime starch from chlorinated wheat flour. Cereal Chem. 1984;61:241-3.

\section{*Corresponding author:}

Masaharu Seguchi,

Faculty of Home Economics,

Laboratory of Food Technology,

Kobe Women's University,

Suma-ku, Kobe City 654-8585

Japan

Tel: 0774-32-7949

Fax: 0774-32-7949

E-mail: gr228587@wf7.so-net.ne.jp 